УДК 379.816

\title{
P. P. Мингареева
}

ФГАОУ ВО «Сибирский федеральный университет», Красноярск, e-mail: rumiya1998@mail.ru

\section{A. B. Haponamoвa}

ФГАОУ ВО «Сибирский федеральный университет», Красноярск;

ФГБОУ ВО «Красноярский государственный аграрный университет», Красноярск, e-mail: sharopatova@yandex.ru

\section{К. Е. Ожсибесова}

ФГАОУ ВО «Сибирский федеральный университет», Красноярск, e-mail: ksenya.ozhgibesova@mail.ru

\section{С. Р. Сондуева}

ФГАОУ ВО «Сибирский федеральный университет», Красноярск, e-mail: seseg7398@gmail.com

\section{СОВРЕМЕННОЕ СОСТОЯНИЕ ОБЬЕКТОВ \\ ДОСУГОВЫХ ОРГАНИЗАЦИЙ \\ ДЛЯ ДЕТЕЙ ДОШКОЛЬНОГО ВОЗРАСТА \\ В Г. КРАСНОЯРСКЕ И НАПРАВЛЕНИЯ ИХ ДЕЯТЕЛЬНОСТИ}

Ключевые слова: досуг, досуговые организации, дошкольные образовательные организации, дети дошкольного возраста, объект недвижимости.

В статье представлены результаты исследования авторского коллектива по анализу объектов досуговых организаций для детей дошкольного возраста в городе Красноярске. Актуальность данной работы связана с проблемой низкой обеспеченности и доступности объектов досуговых организаций для детей дошкольного возраста. В условиях современного мира наблюдается рост численности детей дошкольного возраста, одной из потребностей которых является организация досуга. Целью исследования является оценка современного состояния объектов досуговых организаций для детей дошкольного возраста в г. Красноярске и характеристика направлений их деятельности. Данный анализ проводился для изучения социально-демографических условий города, а также для определения основных проблем развития объектов досуговых организаций в городе Красноярске. Основные методы исследования - статистический анализ. В качестве основного территориального объекта рассматривался город Красноярск Красноярского края. Представлены: динамика численности детей дошкольного возраста и динамика рождаемости детей в городе Красноярске, данные фактического количества объектов досуговых организаций и негосударственных дошкольных организаций, а также фактического количества организаций отдыха и оздоровления детей. В качестве результатов исследования можно выделить оценку объектов досуговых организаций в городе Красноярске и характеристику основных направлений их деятельности.

\section{R. R. Mingareeva}

Siberian Federal University, Krasnoyarsk, e-mail: rumiya1998@mail.ru

\section{A. V. Sharopatova}

Siberian Federal University, Krasnoyarsk;

Krasnoyarsk State Agrarian University, Krasnoyarsk, e-mail: sharopatova@yandex.ru

\section{K. E. Ozhgibesova}

Siberian Federal University, Krasnoyarsk, e-mail: ksenya.ozhgibesova@mail.ru

\section{S. R. Sondueva}

Siberian Federal University, Krasnoyarsk, e-mail: seseg7398@gmail.com

\section{THE CURRENT STATE OF THE FACILITIES OF LEISURE ORGANIZATIONS FOR PRESCHOOL AGE IN THE CITY OF KRASNOYARSK AND THEIR DIRECTIONS OF THEIR ACTIVITY}

Keywords: leisure, leisure organizations, preschool educational organizations, preschool children, real estate object.

The article presents the results of the research of the team of authors on the analysis of objects of leisure organizations for preschool children in the city of Krasnoyarsk. The relevance of this work is associated with 
the problem of low availability and accessibility of objects of leisure organizations for preschool children. In the conditions of the modern world, there is an increase in the number of preschool children, one of whose needs is the organization of leisure. The aim of the study is to assess the current state of facilities of leisure organizations for preschool children in Krasnoyarsk and characterize the directions of their activities. This analysis was carried out to study the socio-demographic conditions of the city, as well as to determine the main problems of the development of facilities for leisure organizations in the city of Krasnoyarsk. The main research methods are statistical analysis. The city of Krasnoyarsk of the Krasnoyarsk Territory was considered as the main territorial object. The following are presented: the dynamics of the number of preschool children and the dynamics of the birth rate of children in the city of Krasnoyarsk, data on the actual number of objects of leisure organizations and non-state preschool organizations, as well as the actual number of recreation and recreation organizations for children. As the results of the study, one can single out the assessment of objects of leisure organizations in the city of Krasnoyarsk and the characteristics of the main directions of their activities.

\section{Введение}

Дети дошкольного возраста - категория людей с разнообразным спектром потребностей, начиная от получения дошкольного образования до проведения досуга в свободное время. Досуг - часть социального свободного времени, отличная от производственной деятельности. Досуговые организации позволяют дошкольникам восстановить физические и психические силы в ходе проведения различных занятий: игры, общение с другими детьми, творческие мероприятия, спорт и другое. Данная статья направлена на исследование досуговых организаций, размещаемых в определенных видах объектов недвижимости. Определены направления деятельности досуговых организаций. Использованы статистические методы по изучению данных объектов в городе Красноярске. Рассмотрены нормативные правовые документы, содержащие основные требования к организациям воспитания и обучения, отдыха и оздоровления детей, а также муниципальная программа, направленная на развитие образования, в частности, организацию отдыха и занятости детей в каникулярное время. В результате данного исследования отмечена основная роль досуга в развитии детей дошкольного возраста. Полученная характеристика досуговых организаций для детей дошкольного возраста позволяет увидеть реальную картину «детского мира» и дает общее представление о объектах недвижимости дошкольных организаций.

Цель исследования - оценка современного состояния объектов досуговых организаций для детей дошкольного возраста в г. Красноярске и характеристика направлений их деятельности.

\section{Материал и методы исследования}

В качестве материала исследования были взяты публичные статистические данные основных показателей объектов недви- жимости дошкольного образования и данные из местных нормативно-правовых документов. В качестве методов исследования был использован статистический анализ.

\section{Результаты исследования и их обсуждение}

Досуг представляет собой деятельность, которая направлена на удовлетворение потребностей людей (физических, духовных, социальных) в свободное время. Преимущественно досуг связан с различными видами отдыха и развлечений.

Досуг может быть организован как для взрослых, так и для детей. Для детей досуг обеспечивает дополнительное образование, развитие и самовоспитание.

Таким образом, досуг имеет большое значение в развитии детей и подростков. В процессе досуга ребенку гораздо проще формировать уважительное отношение к себе, даже личные недостатки можно преодолеть посредством досуговой активности $[1,2]$.

Рассмотрим подробно организацию досуга для детей дошкольного возраста в г. Красноярске. Сегодня Красноярск - это современный индустриальный город с уникальной архитектурой. Численность населения на 1 января 2021 года составляла 1093628 человек.

Исследование данной темы начинается с анализа социально-демографических характеристик города Красноярска, а именно с численности детей дошкольного возраста и рождаемости за последние годы [3]. Динамика численности детей дошкольного возраста (0-7 лет) в г. Красноярске в 20162019 гг. представлена на рисунке 1 .

Согласно данным рисунка 1 значительную долю дошкольников занимают дети в возрасте от 3 до 7 лет.

Динамика рождаемости детей в г. Красноярске в 2013-2020 гг. представлена на рисунке 2. 


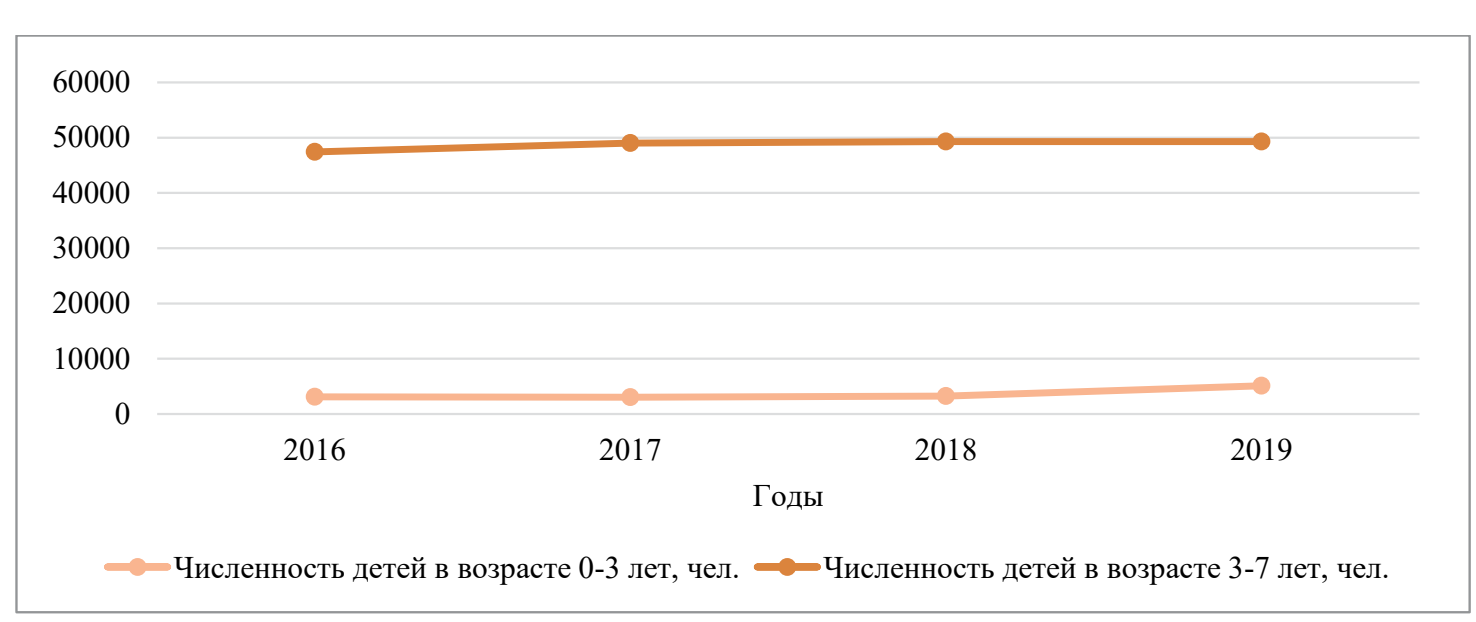

Рис. 1. Динамика численности детей дошкольного возраста (0-7 лет) в г. Красноярске в 2016-2019 г2.

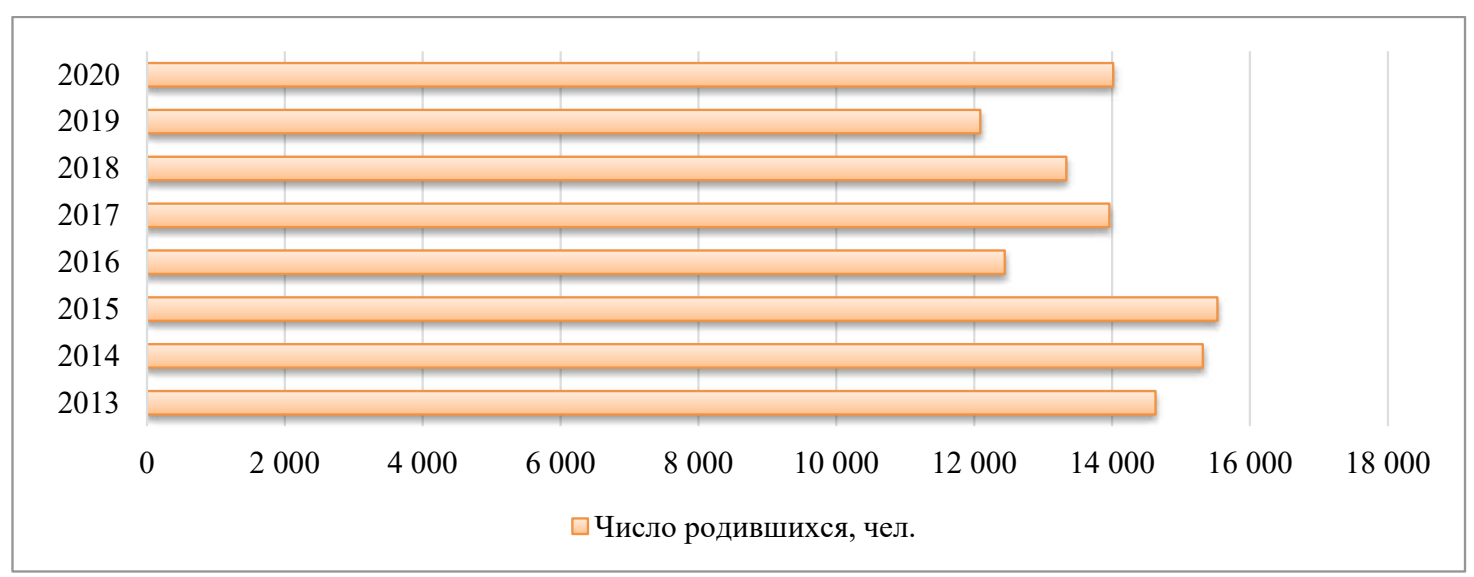

Рис. 2. Динамика рождаемости детей в г. Красноярске в 2013-2020 г2.

Таблица 1

Фактическое количество объектов досуговых организаций для детей дошкольного возраста по районам г. Красноярска на 2021 год

\begin{tabular}{|l|c|}
\hline \multicolumn{1}{|c|}{ Район города } & $\begin{array}{c}\text { Фактическое количество } \\
\text { досуговых организаций } \\
\text { для детей дошкольного } \\
\text { возраста }\end{array}$ \\
\hline Советский & 33 \\
\hline Октябрьский & 18 \\
\hline Ленинский & нет данных \\
\hline Свердловский & 15 \\
\hline Кировский & 6 \\
\hline Железнодорожный & 11 \\
\hline Центральный & 98 \\
\hline Итого: & \\
\hline
\end{tabular}

Источник: составлено авторами по данным источника 4.
Согласно данным рисунка 2 в целом наблюдается рост рождаемости детей в городе. Территория города в административном отношении делится на семь районов: Железнодорожный, Кировский, Ленинский, Октябрьский, Свердловский, Советский и Центральный.

Таким образом, досуг для детей дошкольного возраста в г. Красноярске рассматривается по районам города. В таблице 1 представлено фактическое количество объектов досуговых организаций для детей дошкольного возраста по районам г. Красноярска на 2021 год.

В городе расположено 98 действующих досуговых организаций для детей дошкольного возраста. Такое количество организаций объясняется тем, что:

- часть организаций на сегодняшний день имеют ограниченный режим работы в связи с пандемией COVID-19; 
- большинство досуговых организаций города предоставляют услуги досуга для детей возрастом от 7 лет, т.е. для школьников

- на 2021 год в городе действует большое количество негосударственных дошкольных организаций с услугами присмотра и ухода за детьми, а также дополнительными услугами по развитию ребенка (при существующей проблеме низкой обеспеченности и доступности объектов дошкольного образования).

На рисунке 3 представлена карта г. Красноярска с детскими досуговыми центрами.
При этом существует большое множество частных детских садов, различных детских центров в разных районах г. Красноярска. Основным видом деятельности негосударственных дошкольных организаций является присмотр и уход за детьми, а также лицензированная деятельность по предоставлению дошкольного образования. В качестве дополнительной деятельности выделяют платные услуги логопеда, психолога, дефектолога, обучение иностранным языкам и др.

Негосударственные дошкольные организации в районах г. Красноярска на 2021 год представлены в таблице 2 .

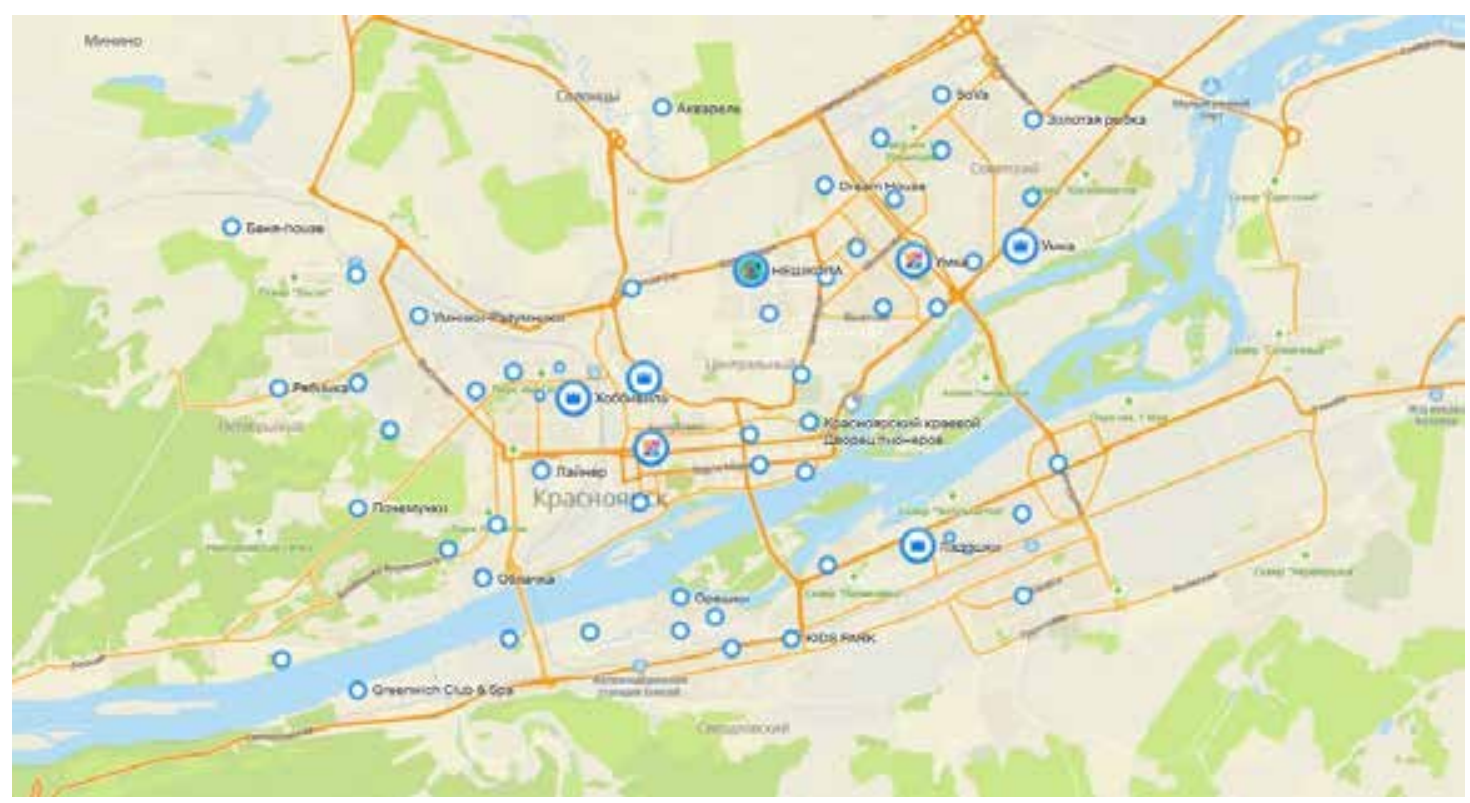

Рис. 3. Карта г. Красноярска с детскими досуговыми центрами

Таблица 2

Негосударственные дошкольные организации в районах г. Красноярска на 2021 год

\begin{tabular}{|c|c|c|c|}
\hline \multirow[b]{2}{*}{ Район города } & \multirow[b]{2}{*}{$\begin{array}{c}\text { Количество } \\
\text { негосударственных } \\
\text { дошкольных организаций }\end{array}$} & \multicolumn{2}{|r|}{ в том числе } \\
\hline & & $\begin{array}{c}\text { Частные } \\
\text { детские сады }\end{array}$ & $\begin{array}{c}\text { Центры развития, } \\
\text { развивающие, семейные } \\
\text { и образовательные центры }\end{array}$ \\
\hline Советский & 165 & 57 & 108 \\
\hline Октябрьский & 79 & 16 & 30 \\
\hline Ленинский & 21 & 4 & 17 \\
\hline Свердловский & 55 & 20 & 35 \\
\hline Кировский & 22 & 8 & 14 \\
\hline Железнодорожный & 24 & 11 & 13 \\
\hline Центральный & 58 & 27 & 31 \\
\hline Итого: & 391 & 143 & 248 \\
\hline
\end{tabular}

Источник: составлено авторами по данным источника 4. 
Значительная часть негосударственных дошкольных организаций располагается на 1 этаже многоэтажных жилых домов, 24 в административных зданиях, 14 - в частных жилых домах (Центральный и Октябрьский районы) и 5 - в отдельных стоящих зданиях. Часть таких организаций имеют лицензию на право оказания образовательных услуг. Динамика количества зданий дошкольных образовательных учреждений представлена реорганизацией существующих образовательных учреждений в форме присоединения к другой организации и строительством новых [5].

По данным [8] можно выделить основные виды деятельности досуговых организаций для детей дошкольного возраста в г. Красноярске на 2021 год:

- организация детских праздников с шоу-программами;

- игровые зоны;

- организация квестов для детей;

- организация мастер-классов для детей;

- научные шоу-программы (центры науки и техники, технопарки);

- спортивные секции (школа балета и гимнастики, школа плавания, карате и т.п.;

- школы танцев;

- музыкальные центры и центры вокала;

- художественные студии;

- модельная школа.

Тем самым можно объединить виды досуга для дошкольников по следующим основным направлениям:

- проведение праздничных мероприятий и познавательных мастер-классов;

- посещение спортивных секций;

- посещение творческих центров.

Среди досуга для дошкольников в каникулярное время можно выделить детские лагеря. Развитию данного досуга способствует принятие нормативно-правовых актов в сфере образования.

Так в городе Красноярске утверждена муниципальная программа «Развитие образования в городе Красноярске» на 2021 год и плановый период 2022-2023 годов», направленная на повышение качества организации предоставления общедоступного и бесплатного начального общего, основного общего, среднего общего образования по основным общеобразовательным программам, дополнительного образования, общедоступного бесплатного дошкольного образования на территории города Красноярска, отдыха и оздоровления детей.
Среди подпрограмм - организация отдыха и занятости детей в каникулярное время. Целью данной подпрограммы является создание необходимых и достаточных условий для полноценного оздоровления, отдыха и занятости детей и подростков в каникулярное время [6].

Также приняты СП 2.4.3648-20 «Санитарно-эпидемиологические требования к организациям воспитания и обучения, отдыха и оздоровления детей и молодежи».

Настоящие СП направлены, в первую очередь, на охрану здоровья детей и молодежи, а также на создание безопасных условий образовательной деятельности, ухода и присмотра за детьми, проведения спортивных, художественных и культурно-массовых мероприятий и т.п.

Среди основных требований данных правил можно выделить следующее:

- обеспечение наружного электрического освещения, ограждения и зеленых насаждений в случае наличия собственной территории;

- не допускается в подвальных и цокольных этажах размещать комнаты для детей и молодежи, комнаты оказания медицинской помощи, кроме гардеробов, туалетов для персонала, тира, помещений для хранения книг, умывальных и душевых помещений, и иных хозяйственных и подсобных помещений;

- минимальный набор помещений с круглосуточным пребыванием: спальные комнаты; комнаты воспитателя; помещения для дневного пребывания детей; умывальные; душевые; помещение для просушивания одежды и обуви, помещение стирки и глажения; помещение для обработки и хранения уборочного инвентаря; помещение гладильной; место для хранения обуви;

- наличие технологического, холодильного и моечного оборудования, инвентаря в помещениях для приготовления и приема пищи, хранения пищевой продукции, а также соблюдение технологии приготовления блюд, режима обработки, условий хранения пищевой продукции;

- при проведении физкультурных, физкультурно-оздоровительных мероприятий, массовых спортивных мероприятий, туристических походов, спортивных соревнований учитывается возраст, физическая подготовленность и состояние здоровья детей и др. [7]. 
Несмотря на географическое положение, в Красноярском крае располагается довольно большое число детских лагерей, а также детских оздоровительных кампаний на высоком уровне. Летом в крае работает более 1000 детских лагерей различных типов.

В летний период отдых ребят в крае организуется в детских оздоровительных учреждениях нескольких типов:

- на базе 63 загородных оздоровительных и санаторных лагерей;

- в более чем 770 лагерях с дневным пребыванием, которые функционирует на базе оздоровительных учреждений;

- в туристических палаточных лагерях, которых в крае насчитывается более 200.
В итоге, различными формами отдыха, оздоровления и занятости оказываются охвачены более 230 тысяч юных красноярцев. Также большое количество детских лагерей сформировано на базе общеобразовательных учреждений, количество которых на 2021 год в г. Красноярске составляет - 113.

Основными задачами в сфере детского отдыха являются укрепление материально-технической базы загородных лагерей, а также обеспечение безопасных условий оздоровительных кампаний. Но для дошкольников в силу возраста существует лишь несколько детских лагерей и только для детей возрастом от 5 лет. Организации отдыха и оздоровления детей в округе г. Красноярска на 2021 год представлены в таблице 3.

Таблица 3

Организации отдыха и оздоровления детей в округе г. Красноярска на 2021 год

\begin{tabular}{|c|c|}
\hline Наименование организации & Описание \\
\hline $\begin{array}{l}\text { Детский оздоровительный лагерь } \\
\text { «Гренада» }\end{array}$ & $\begin{array}{l}\text { Санаторно-оздоровительный комплекс, располагается в районе по- } \\
\text { селка Базаиха, с количеством } 484 \text { места }\end{array}$ \\
\hline Лагерь «Жарки» & $\begin{array}{l}\text { Подведомственный лагерь министерства социальной политики } \\
\text { края, располагается в Рыбинском районе. С количеством } 570 \text { мест } \\
\text { для детей в возрасте от } 6 \text { до } 16 \text { лет }\end{array}$ \\
\hline $\begin{array}{l}\text { Детский оздоровительный лагерь } \\
\text { «Зеленые горки» }\end{array}$ & $\begin{array}{l}\text { Располагается в Манском районе, д.Правый, с количеством мест - } \\
220\end{array}$ \\
\hline $\begin{array}{l}\text { Детский оздоровительный лагерь } \\
\text { «Инголь» }\end{array}$ & $\begin{array}{l}\text { Располагается на расстоянии } 30 \text { километров от города Шарыпово с } \\
\text { количеством мест - } 160\end{array}$ \\
\hline Детский лагерь «КОНКВЭСТ» & $\begin{array}{l}\text { Проведение занятий в самых разных сферах и видах деятельности - } \\
\text { изучение иностранных языков, яхтинг, верховая езда, квадроциклы. } \\
\text { Местоположение: яхт-клуб «АДМИРАЛ» и б/о «Горная Саланга }\end{array}$ \\
\hline $\begin{array}{l}\text { Детский оздоровительный лагерь } \\
\text { «Красэйр» }\end{array}$ & $\begin{array}{l}\text { Иучение английского языка. Местоположение: г. Красноярск, ул. Ба- } \\
\text { зайская, } 353\end{array}$ \\
\hline Лагерь «Солнечный-2» & $\begin{array}{l}\text { Автономное учреждение «Комплексный центр социального обслу- } \\
\text { живания «Тесь» Министерства социальной политики. Количество } \\
\text { мест - 730. Местоположение: Красноярский край, Минусинский } \\
\text { район, с. Тесь; }\end{array}$ \\
\hline $\begin{array}{l}\text { Детский оздоровительный лагерь } \\
\text { «Юность» }\end{array}$ & $\begin{array}{l}\text { Располагается в Емельяновском районе Красноярского края. Коли- } \\
\text { чество мест составляет } 100\end{array}$ \\
\hline $\begin{array}{l}\text { Летний городской лагерь дневного } \\
\text { пребывания «SuperCamp» }\end{array}$ & $\begin{array}{l}\text { Для детей 5-12 лет в ЦДТ «Золотое яблоко» (г. Красноярск, ул. Вес- } \\
\text { ны, д. 2А) }\end{array}$ \\
\hline Лагерь «Клик» & $\begin{array}{l}\text { В программе: квесты, экскурсии, просмотр кино, посещение бас- } \\
\text { сейна, театров и музеев, игры на свежем воздухе и английский язык. } \\
\text { Для детей от } 5 \text { до } 14 \text { лет. Адрес: Красноярск, ул. Авиаторов, д. } 44\end{array}$ \\
\hline Лагерь «Богатырская Застава» & $\begin{array}{l}\text { Проведение культурно-спортивной каникулярной программы для } \\
\text { детей 6-12 лет. Программа длится } 5 \text { дней и включает в себя: тре- } \\
\text { нировки, сражения, походы, исторические квесты, мастер-классы, } \\
\text { ремесленные поделки, экскурсии и многое другое (г. Красноярск, } \\
\text { пр. Свободный, д.95) }\end{array}$ \\
\hline
\end{tabular}

Источник: составлено авторами по данным источника 8. 
Можно сделать вывод, что в г. Красноярске располагается лишь небольшое количество различных досуговых организаций для детей дошкольного возраста, расположенных в жилых и общественных зданиях, так как досуг для дошкольников в большей степени имеет игровую форму, нежели познавательно-обучающую.

Основным направлением решения данной проблемы является увеличение количества досуговых организаций с расширением спектра услуг, включая создание открытых «зеленых» площадок с проведением различных мероприятий и большего времени детей на свежем воздухе. Тем самым будет решаться задача создания необходимых и достаточных условий для полноценного оздоровления, отдыха и занятости детей и подростков в каникулярное время.

\section{Заключение}

Таким образом представлена общая характеристика досуга для детей дошкольного возраста. При оценке современного состояния досуговых организаций, выявлено, что в г. Красноярске расположены различные досуговые организации с широким спектром направлений их деятельности. Но несмотря на большую численность дошкольников, в целом существующая численность объектов досуговых организаций не обеспечивает услугами досуговых мероприятия всех детей дошкольного возраста в силу разного уровня развития ребенка.

\section{Библиографический список}

1. Ярошевич Т.М. Досуг: теоретические аспекты, структура, содержание // Научное периодическое сетевое издание «Гуманитарные, социально-экономические и общественные науки. 2014. № 1.

2. Мингареева Р.Р., Шаропатова А.В. Проблемы развития объектов дошкольного образования в городе Красноярске // Инвестиции, градостроительство, недвижимость как драйверы социально-экономического развития территории и повышения качества жизни населения: материалы XI Международной научнопрактической конференции (Томск, 2-4 марта 2021 г.). Томск: Издательство Томского государственного архитектурно-строительного университета, 2021. С. 329-334.

3. Управление Федеральной службы государственной статистики по Красноярскому краю, Республике Хакасия и Республике Тыва. [Электронный ресурс]. URL: https://krasstat.gks.ru.

4. Министерство образования Красноярского края. [Электронный ресурс]. URL: https://krao.ru.

5. Мингареева Р.Р., Шаропатова А.В., Васильева А.А., Кожевникова М.С., Ожгибесова К.Е. Текущее техническое состояние зданий ДОО как проблема развития объектов дошкольного образования (на примере города Красноярска) // Московский экономический журнал. 2021. № 4.

6. Постановление Администрации города Красноярска от 12 ноября 2020 года № 897 «Об утверждении муниципальной программы Развитие образования в городе Красноярске на 2021 год и плановый период 2022-2023 годов».

7. Постановление Главного государственного санитарного врача РФ от 28 сентября 2020 года № 28 «Об утверждении санитарных правил СП 2.4.3648-20 Санитарно-эпидемиологические требования к организациям воспитания и обучения, отдыха и оздоровления детей и молодежи».

8. Информационный сервис-справочник KidsReview. [Электронный pecypc]. URL: https://www. kidsreview.ru. 